\title{
Two-dimensional patterns in neural fields subject to finite transmission speed
}

\author{
Eric Nichols ${ }^{1 *}$, Kevin Green ${ }^{1,2}$, Axel Hutt ${ }^{1}$, Lennaert van Veen ${ }^{2}$ \\ From The Twenty Third Annual Computational Neuroscience Meeting: CNS*2014 \\ Québec City, Canada. 26-31 July 2014
}

This work analyzes and implements finite axonal transmission speeds in two-dimensional neural populations. The biological significance of this is found in the rate of spatiotemporal change in voltage across neuronal tissue, which can be attributed to phenomena such as delays in spike propagation within axons, neurotransmitter activation and the time courses of neuron polarization and refraction. The authors build upon the finite transmission speed work in [1].

Linear analysis about a spatially homogeneous resting state of the neural population dynamics is performed. The analyses of the resulting analytical expressions guide the parameter selection for simulations. For simulation, computation of the transmission-delayed convolution between the kernel and firing rates is performed with a fast Fourier transform as in [1].

The Neural Field Simulator [2] is used to simulate the activity of the field. We extended the simulator by the implementation of a large class of kernels reflecting global excitation, global inhibition, local excitation-lateral inhibition and local inhibition-lateral excitation. Moreover, we extended the tools by an automatic root finder to compute stationary states and an automatic root finder of the characteristic equation of the linear dynamics. These latter features facilitate the user to perform the linear analysis. Further adjustments to the simulator include a provision to modify neural field variables online while simulations are ongoing and three-dimensional displays of disparate parts of the neural field, such as the external input, kernel and firing rate.

We find Turing patterns appear when starting the simulations with the derived conditions for stationary instability. This is shown in Figure 1(A,B,C). Simulations with travelling wave patterns are also performed using parameter sets for the non-stationary instabilities, and the effects of finite transmission speeds are analyzed and visualized. The software tool provides a large set of analysis and visualization tools, that promises to speed up

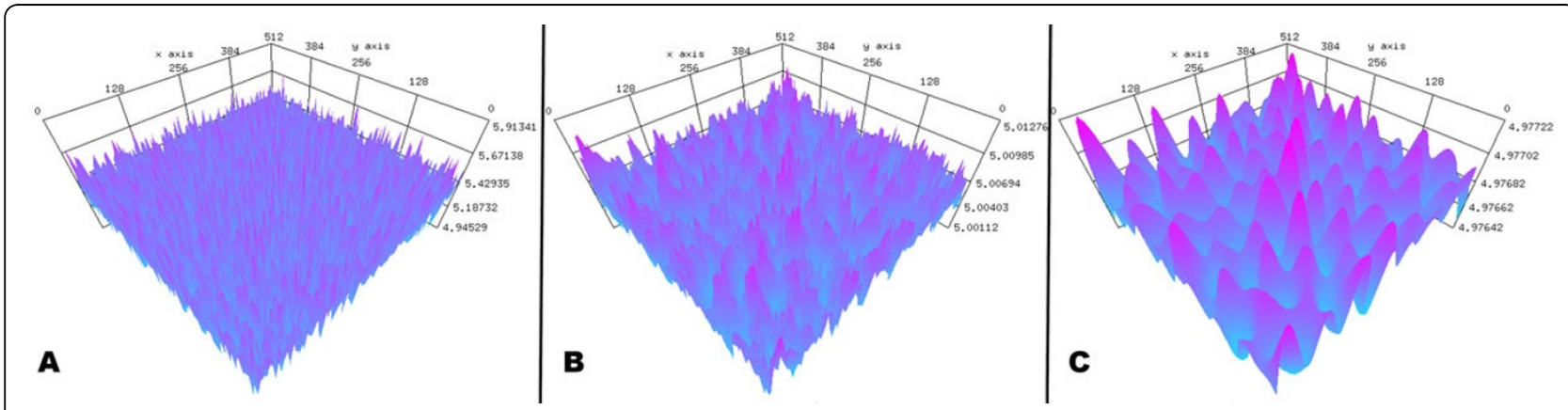

Figure 1 A neural field simulation. A noisy field A evolving B into a Turing pattern $\mathbf{C}$.

\footnotetext{
* Correspondence: eric.nichols@inria.fr

${ }^{1}$ INRIA Nancy, Team NeuroSys, 615 rue du Jardin Botanique, 54600 Villers-lès-

Nancy, France

Full list of author information is available at the end of the article
} 
the analysis of two-dimensional neural field dynamics and hence accelerates research on neural population dynamics.

\section{Acknowledgements}

This work is funded by the European Research Council for support under the European Union's Seventh Framework Programme (FP7/2007-2013), ERC grant agreement No. 257253 (MATHANA project).

\section{Authors' details}

'INRIA Nancy, Team NeuroSys, 615 rue du Jardin Botanique, 54600 Villers-lèsNancy, France. ${ }^{2}$ Faculty of Science, University of Ontario Institute of

Technology, 2000 Simcoe Street North, Oshawa, L1H 7K4 Ontario, Canada.

Published: 21 July 2014

\section{References}

1. Hutt A, Rougier N: Activity spread and breathers induced by finite transmission speeds in two-dimensional neural fields. Physical Review E: Statistical, Nonlinear, and Soft Matter Physics 2010, 82(5):R055701.

2. Nichols EJ, Hutt A: Neural field simulator: fast computation and 3Dvisualization. Twenty Second Annual Computational Neuroscience Meeting, Paris, France 2013, 14:179.

doi:10.1186/1471-2202-15-S1-P16

Cite this article as: Nichols et al:: Two-dimensional patterns in neural

fields subject to finite transmission speed. BMC Neuroscience 2014

15(Suppl 1):P16.

\section{Submit your next manuscript to BioMed Central} and take full advantage of:

- Convenient online submission

- Thorough peer review

- No space constraints or color figure charges

- Immediate publication on acceptance

- Inclusion in PubMed, CAS, Scopus and Google Scholar

- Research which is freely available for redistribution

Submit your manuscript at www.biomedcentral.com/submit 